\title{
Effects of Dopants on the Structure and Properties of Electroconductive Composite Film of Polypyrrole and Aramid
}

\author{
Keiko KogA, Takao IINo, Shigeyuki UETA, \\ and Motowo TAKAYANAGI \\ Faculty of Engineering, Kyushu Sangyo University, Matsukadai, \\ 2-3-1, Higashi-ku, Fukuoka 813, Japan
}

(Received February 6, 1989)

\begin{abstract}
A conductive polymer composite of polypyrrole (PPy) and poly ( $p$-phenylene terephthalamide) (PPTA) was prepared by the electropolymerization of pyrrole on an electrode covered with PPTA film prepared by the electrodeposition of PPTA polyanion in dimethylsulfoxide (DMSO) as reported in our previous paper. The supporting electrolyte used during electropolymerization of pyrrole was tetraethylammonium $p$-toluensulfonate $\left(\mathrm{TsO}^{-}\right)$. Treatment of the $\mathrm{PPy}\left(\mathrm{TsO}^{-}\right)$/PPTA composite with hydrochloric acid provided a more thermally stable and mechanically improved composite film than that untreated with hydrochloric acid. The effect of $\mathrm{HCl}$-treatment for single $\mathrm{PPy}\left(\mathrm{TsO}^{-}\right)$was investigated by X-ray photoelectron spectroscopy (XPS) and X-ray diffraction measurement. XPS proved that the dopant of $p$-toluensulfonate anion was partly exchanged for chlorine anion. X-Ray diffraction proved that the interplanar distance of PPy molecules and intercalation layer thickness decreased with hydrochloric acid treatment. These results led us to consider that improvement of the composite film by the $\mathrm{HCl}$-treatment is mainly attributable to structural change in poly(pyrrolylium anion).
\end{abstract}

KEY WORDS Poly( $p$-phenylene terephthalamide)/ Polypyrrole / Conductivity / Dopant / Composite /

The electropolymerization of conductive polymers such as polypyrrole (PPy) on the electrode covered with insulating polymers provides conductive composite films. ${ }^{1-5}$ These composites showed improved mechanical properties or light transparency or anisotropy of conductivity. We reported in a previous $\operatorname{paper}^{6}$ that a poly( $p$-phenylene terephthalamide) (PPTA) film having excellent mechanical properties and heat-resistance was used for a host polymer of a conductive composite with polypyrrole (PPy). The composite film of PPy and PPTA thus obtained became stronger, stiffer and more thermally stable in comparison with the single PPy film. ${ }^{6}$ PPTA film can be prepared by electrolysis of PPTA polyanion ionized by sodium methylsulfinylcarbanion in a solution of dimethylsulfoxide (DMSO). The PPTA as- electrodeposited is in a gel state swollen by DMSO. $^{7}$ The crystallinity and content of remaining solvent of the PPTA film were controlled by washing and annealing in the process of film formation from the gel. With appropriate selection of these conditions, the obtained film of PPTA can be used for a host polymer of the composite film. ${ }^{6}$

The polymerization of pyrrole took place easily in the PPTA film prepared by washing the PPTA gel as-electrodeposited with acetonitrile. But sodium cations which replaced the amide protons of PPTA molecules through the reaction of the reagent of sodium methylsulfinylcarbanion were included in the PPTA film prepared in this procedure. During the electropolymerization of pyrrole in the PPTA film using tetraethylammonium $p$-toluenesulfonate as an electrolyte, the $p$-toluenesul- 
fonate anions $\left(\mathrm{TsO}^{-}\right)$in part combined the sodium cations to form a salt which was shown by the X-ray diffraction pattern of the composite film to give several sharp peaks. Washing of the PPTA gel as-electrodeposited with hydrochloric acid removed the sodium cations thoroughly from the gel, resulting in sodium salt-free composite film. In this paper, we used the latter PPTA film as a host polymer of a composite.

Increased electroconductivity, improved mechanical properties and thermat stability of the composite film by hydrochloric acid treatment after composite formation, are discussed based on structural characterization.

\section{EXPERIMENTAL}

\section{Preparation of Composite Film}

The preparation of PPTA film was conducted by the electrolysis of a solution of PPTA polyanion in DMSO using sodium hydride and DMSO according to the method of Takayanagi-Katayose. ${ }^{8}$ Electrolysis was conducted using a rotating stainless steel anode with a $2.5 \mathrm{~mA} \mathrm{~cm}^{-2}$ current density for $7 \mathrm{~min}$. A PPTA gel swollen by DMSO was obtained on the anode as in the previous paper. ${ }^{7}$ Treatment of the gel was conducted by washing with aqueous $1 \mathrm{~N}-\mathrm{HCl}$, water and acetonitrile in this order. The treated gel was dried on an ITO-glass to form an electrode covered with PPTA film $16 \mu \mathrm{m}$ thick. Using this electrode as the anode, electropolymerization of pyrrole was conducted in a two-electrode cell for $10 \mathrm{~min}$ at constant potential of $5 \mathrm{~V}$, using an acetonitrile solution of $1 \mathrm{ML}^{-1}$ of pyrrole and $0.3 \mathrm{ML}^{-1}$ of tetraethylammonium $p$ toluenesulfonate. After washing the film with acetonitrile, peeling and drying, the composite film was obtained. Hydrochloric acid treatment after composite formation was conducted by soaking it in aqueous $1 \mathrm{~N}-\mathrm{HCl}$ for one day followed by washing with water and drying.

\section{Characterization of Composite Film}

Surface resistance was measured by the four probe method and conductivity was evaluated. The thermal stability of the conductivity was estimated by measuring the surface resistance at room temperature after annealing at temperatures covering a range of $40-225^{\circ} \mathrm{C}$ for $10 \mathrm{~min}$. The same specimen was successively subjected to annealing and measurements. XRay diffraction was measured with a wide angle plate camera and diffractometer (Rigaku, Geiger flex RAD IIIA) in a reflection mode using $\mathrm{Cu} K_{\alpha}$ radiation. Mechanical properties were measured by a Tensilon tensile tester (Orientec, Model STM-50BT). The morphology of the composite was studied by scanning electron microscopy (SEM) (Hitachi S510). X-Ray photoelectron spectroscopy (XPS) (Shimadzu ESCA 750) was used for evaluation of the elemental composition of the composite film.

\section{RESULTS AND DISCUSSION}

Figure 1 shows the variation in the surface resistance of the composite film of $\mathrm{PPy}\left(\mathrm{TsO}^{-}\right) /$ PPTA after annealing at the temperatures indicated on the abscissa for the samples untreated (open circles) and treated (filled circles) with hydrochloric acid. Measurement was made on the surface of the electrode side during the electropolymerization of pyrrole.

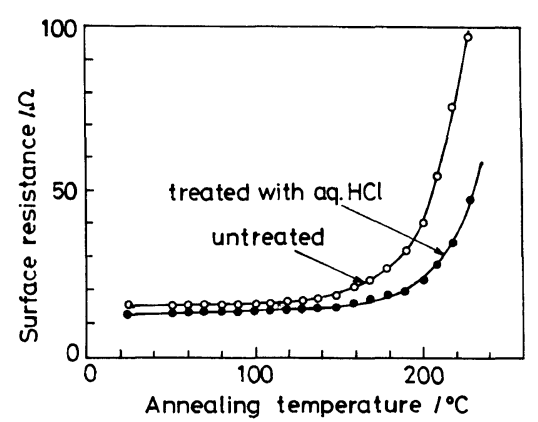

Figure 1. Thermal stabilities of the surface resistance for $\mathrm{PPy}\left(\mathrm{TsO}^{-}\right)$/PPTA composite films untreated and treated with aq $\mathrm{HCl}$. 


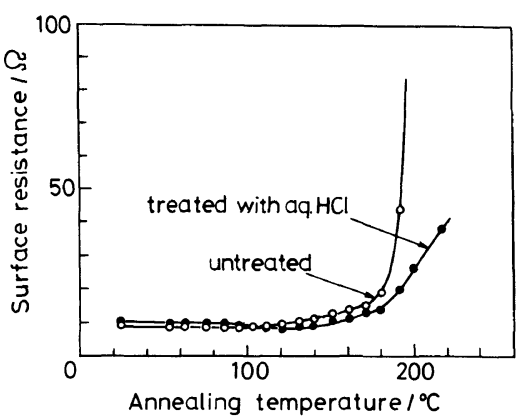

Figure 2. Thermal stabilities of the surface resistance for single $\mathrm{PPy}\left(\mathrm{TsO}^{-}\right)$films untreated and treated with aq $\mathrm{HCl}$.

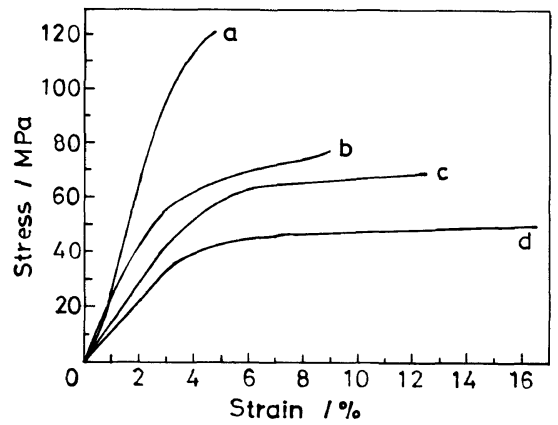

Figure 3. Stress-strain curves for the composite film treated with aq $\mathrm{HCl}$ (a) and untreated (b), and the single PPy film treated with aq $\mathrm{HCl}$ (c) and untreated (d).

PPy reached the film surface of the solution side under this polymerization condition. The surface resistance of the untreated sample increased rapidly above $150^{\circ} \mathrm{C}$ as in the previous paper. ${ }^{6}$ In contrast to this, the surface resistance of the composite treated with $\mathrm{HCl}$ retained its value up to a temperature higher than the former. The thermal stability of the composite increased by $\mathrm{HCl}$-treatment after the polymerization of pyrrole. Figure 2 shows the effect of $\mathrm{HCl}$-treatment for a single film of $\mathrm{PPy}\left(\mathrm{TsO}^{-}\right)$. The thermal stability of $\mathrm{PPy}\left(\mathrm{TsO}^{-}\right)$itself increased by $\mathrm{HCl}$-treatment. In the composite film, both the effects of PPy itself and composite formation are considered to be effective additively.

The effects of $\mathrm{HCl}$-treatment on the mechanical properties were surveyed for the sin-
Table I. Mechanical properties and conductivities of $\mathrm{PPy}\left(\mathrm{TsO}^{-}\right) / \mathrm{PPTA}$ composite and single $\mathrm{PPy}\left(\mathrm{TsO}^{-}\right)$

\begin{tabular}{|c|c|c|c|}
\hline & $\begin{array}{c}\text { Tensile } \\
\text { modulus }\end{array}$ & $\begin{array}{l}\text { Tensile } \\
\text { strength }\end{array}$ & Conductivity \\
\hline & $\mathrm{GPa}$ & $\mathrm{MPa}$ & $\mathrm{Scm}^{-1}$ \\
\hline $\mathrm{PPy}\left(\mathrm{TsO}^{-}\right)$untreated & 1.22 & 49.4 & 114 \\
\hline $\begin{array}{c}\mathrm{PPy}\left(\mathrm{TsO}^{-}\right) \text {treated } \\
\text { with aq } \mathrm{HCl}\end{array}$ & 1.52 & 68.1 & 240 \\
\hline PPy/PPTA untreated & 3.35 & 91.0 & 4.1 \\
\hline $\begin{array}{c}\text { PPy/PPTA treated } \\
\text { with aq } \mathrm{HCl}\end{array}$ & 4.12 & 121 & 7.0 \\
\hline
\end{tabular}
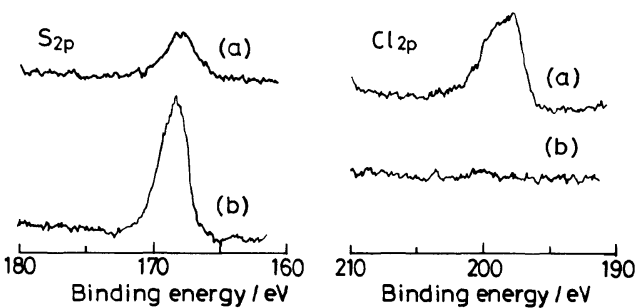

Figure 4. XPS core level spectra of $\mathrm{PPy}\left(\mathrm{TsO}^{-}\right.$) (a) treated with aq $\mathrm{HCl}$ and (b) the untreated one.

gle $\mathrm{PPy}\left(\mathrm{TsO}^{-}\right)$film and composite film of $\mathrm{PPy}\left(\mathrm{TsO}^{-}\right) / \mathrm{PPTA}$. Figure 3 shows the stressstrain curves for these samples. Comparisons between curves $a$ and $b$, and $c$ and $d$, respectively, revealed that $\mathrm{HCl}$-treatment equally increased the modulus and strength of the composite film (curve a) and the single PPy film (curve c). The mechanical properties and conductivities of the composite films and single $\mathrm{PPy}\left(\mathrm{TsO}^{-}\right)$films are listed in Table I. The conductivities of both the single PPy and composite films increase after $\mathrm{HCl}$-treatment.

Figure 4 shows the XPS spectra of S2p and $\mathrm{Cl} 2 \mathrm{p}$ for $\mathrm{PPy}\left(\mathrm{TsO}^{-}\right)$single films before (b) and after (a) HCl-treatment. XPS measurement was made on the film surface of the electrode side during the pyrrole polymerization. $\mathrm{HCl}$ Treatment decreased the peak of $S 2 p$ and a peak of $\mathrm{Cl} 2 \mathrm{p}$ newly appeared. These results indicate that $\mathrm{TsO}^{-}$ions as a dopant of PPy are partly replaced by $\mathrm{Cl}^{-}$ions. Table II shows 
Table II. Molar ratio of dopant to one pyrrole ring evaluated from XPS spectra of $\mathrm{PPy}\left(\mathrm{TsO}^{-}\right)$

\begin{tabular}{lll}
\hline & $\mathrm{TsO}^{-}$ & $\mathrm{Cl}^{-}$ \\
\hline $\begin{array}{l}\text { PPy film untreated } \\
\text { PPy film treated with aq }\end{array}$ & 0.32 & 0 \\
$\mathrm{HCl}$ & 0.06 & 0.10 \\
\hline
\end{tabular}

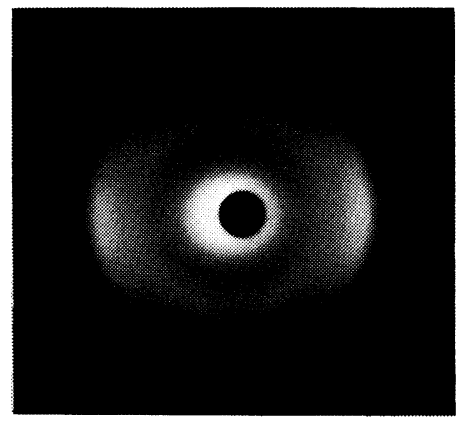

(a)

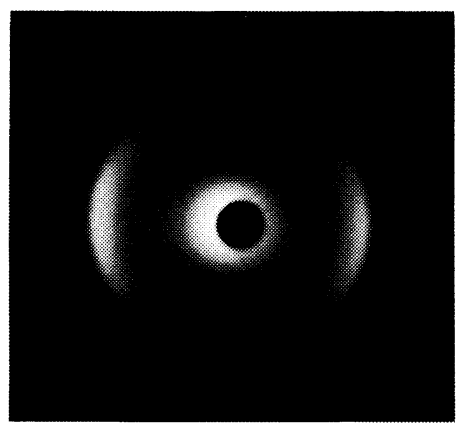

( b )

Figure 5. Wide angle $\mathrm{X}$-ray diffraction photographs of $\mathrm{PPy}\left(\mathrm{TsO}^{-}\right)$film before (a) and after $\mathrm{HCl}$-treatment (b).

dopant content in PPy before and after the $\mathrm{HCl}$-treatment evaluated from these spectra and $\mathrm{N} 1 \mathrm{~s}$ spectra (not shown). After $\mathrm{HCl}$ treatment, the $\mathrm{TsO}^{-}$value decreased and the $\mathrm{Cl}^{-}$value increased. The $\mathrm{TsO}^{-}$value before treatment was somewhat smaller than 0.43 (the unit is the molar ratio for one pyrrole ring) as determined from elemental analysis by Wynne and Street. ${ }^{9}$ The reason for the difference might be the different polymerization conditions and difference between the surface and

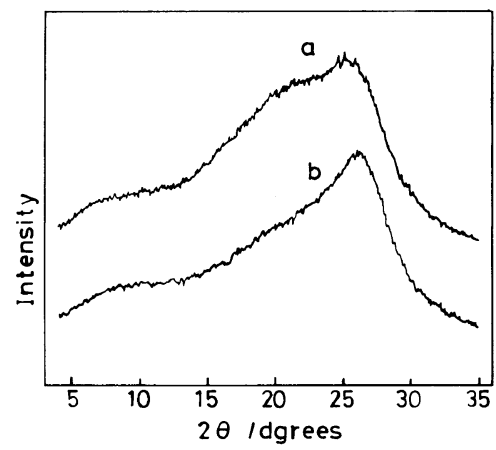

Figure 6. Intensity curves of X-ray diffraction for (a) $\mathrm{PPy}\left(\mathrm{TsO}^{-}\right)$film before (a) and after $\mathrm{HCl}$-treatment (b).

bulk.

Figure 5 shows the X-ray diffraction patterns of the PPy film before and after $\mathrm{HCl}$ treatment. The X-ray beam was parallel to the film surface (edge view). The outer arcs of the equatorial diffraction $\left(2 \theta=26^{\circ}\right)$ correspond to the interplanar distance of the pyrrole rings. ${ }^{9}$ The concentration of the intensity on the equator indicates that the PPy rings lie in the plane of the film. This is consistent with the results in the literature. ${ }^{10,11}$ The intensity of the inner ring decreased by $\mathrm{HCl}$-treatment. This reflection $\left(2 \theta=20-23^{\circ}\right)$ has been assigned to the distance between whether pyrrole and $\mathrm{TsO}^{-}$or $\mathrm{TsO}^{-}$themselves by Wynne and Street. ${ }^{9}$ This assignment seems to be reasonable since the decrease in the intensity was caused by in decrease $\mathrm{TsO}^{-}$as confirmed by XPS measurement. Figure 6 shows the X-ray diffraction intensity curves for the same $\mathrm{PPy}\left(\mathrm{TsO}^{-}\right)$films as shown in Figure 5. From these curves, two points other than the findings from Figure 5 are worth noting. First, $\mathrm{HCl}$ treatment shifted the peak around $2 \theta=26^{\circ}$ slightly toward the higher angle. This indicates that the interplanar distance of pyrrole rings decreased by $\mathrm{HCl}$-treatment. The second point is that the lowest angle peak $\left(2 \theta=7^{\circ}\right.$ before HCl-treatment) shifted to the higher angle side $\left(2 \theta=9^{\circ}\right)$ by $\mathrm{HCl}$-treatment. Buckley et $a l .{ }^{11}$ and Wernet et al. ${ }^{12}$ suggest from the correlation of peak position with various 
counteranions that this peak corresponds to the pyrrole-counteranion intercalation layer thickness, that is, the distance between pyrrole and counteranion aligned side by side. It is of a reasonable explanation from these findings that $\mathrm{Cl}^{-}$ions smaller size are replaced by $\mathrm{TsO}^{-}$ions of larger size, resulting in decreased interplanar distance of pyrrole rings and intercalation layer thickness. Moreover, the decrease of the intercalation layer thickness led to increased conductivity. This agrees with the correlation between the conductivity and distance of the polymer chains reported by Yamaura et al. ${ }^{13}$ for various dopant anions.

On the macroscopic scale, the texture of the single $\mathrm{PPy}\left(\mathrm{TsO}^{-}\right)$film became dense by $\mathrm{HCl}$ treatment as revealed by the fact that the thickness decreased to about $2 / 3$ the original one after $\mathrm{HCl}$-treatment. Such changes in structure and morphology should result in improved thermal stability and mechanical properties of PPy in addition to conductivity. The reason for the exchange of dopants by the simple operation of soaking in an aqueous $\mathrm{HCl}$ solution is explained as follows. The proton of the strong acid of $\mathrm{HCl}$ is bonded with the weak base of $\mathrm{TsO}^{-}$and instead of it the $\mathrm{Cl}^{-}$ion is coordinated to PPy. At the same time, decrease in the intermolecular distance of PPy rings and intercalation layer thickness induces decrease in the total energy of the system.

Improvement in the properties of the single PPy as mentioned above, of course, occurs in the PPy/PPTA composite. The improved conductivity, mechanical properties and thermal stability of the composite after the $\mathrm{HCl}$ treatment are mainly attributable to the improved properties of the single PPy. In addition, PPy was densely packed by $\mathrm{HCl}$ treatment so that the total texture of the composite became compact. This contributes partly to the improved properties of the composite.

Figure 7 shows the SEM photographs of the composite before the $\mathrm{HCl}$-treatment which

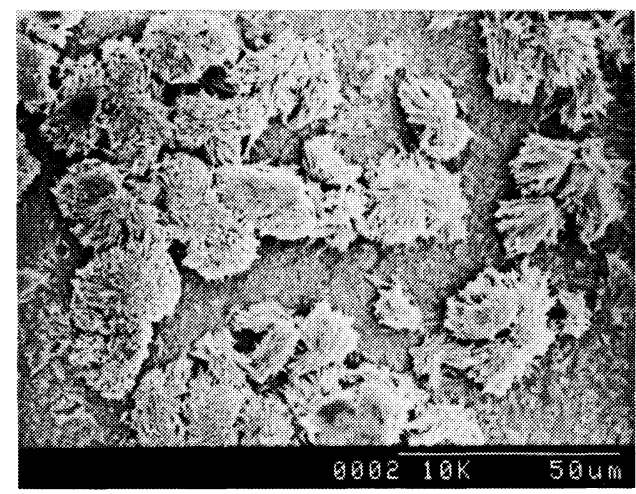

(a) solution side

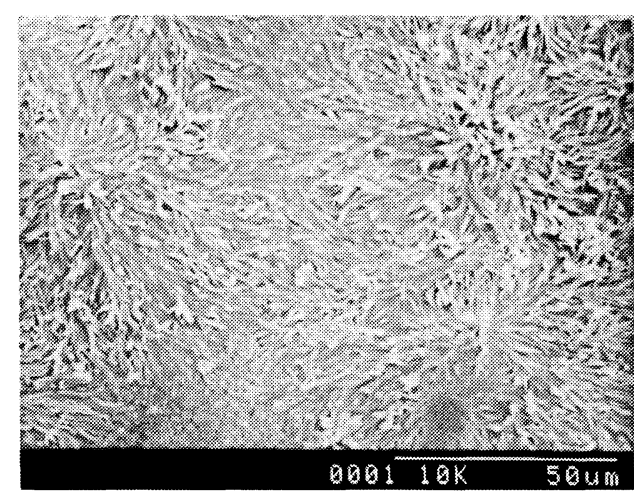

(b) electrode side

Figure 7. SEM photographs of PPy/PPTA composite before $\mathrm{HCl}$-treatment etched by $\mathrm{NaH}-\mathrm{DMSO}$ reagent.

was etched by the NaH-DMSO reagent to remove PPTA. Needle-like PPy grows on both sides of the composite film. This morphology is quite different from the pancake-like particles of PPy in the $\mathrm{PPy}\left(\mathrm{TsO}^{-}\right) / \mathrm{PPTA}$ composite reported in our previous paper. ${ }^{6}$ The difference of morphologies between the two composites is in the preparation procedure of PPTA film; the former is prepared by washing the PPTA gel as-electrodeposited with aqueous $\mathrm{HCl}$ and the latter with acetonitrile. This difference of preparation procedure affects the PPTA texture and the PPy morphology in the composite. 


\section{CONCLUSIONS}

A conductive polymer composite of polypyrrole (PPy) and poly ( $p$-phenylene terephthalamide) (PPTA) was formed by the electropolymerization of pyrrole on the electrode covered with the PPTA film. The treatment of the composite with hydrochloric acid improved the conductivity, mechanical properties and thermal stability. These improvements are mainly ascribed to the structural change of poly(pyrrolylium anion) due to replacement of dopant anion, $p$-toluenesulfonate ions, with chlorine ions by $\mathrm{HCl}$-treatment.

Acknowledgment. The measurement of XPS was conducted at the laboratory of Professor Kajiyama of Kyushu University, to whom we express our thanks. This research was partly supported by a Grant-in-Aid from the Ministry of Education, Science, and Culture of Japan.

\section{REFERENCES}

1. O. Niwa, M. Hikita, and T. Tamamura, Makromol. Chem., Rapid Commun., 6, 375 (1985).

2. M.-A. DePaoli, R. J. Waltman, A. F. Diaz, and J. Bargon, J. Polym. Sci., Polym. Chem. Ed., 23, 1687 (1985).

3. S. E. Linsey and G. B. Street, Synth. Met., 10, 67 (1984/85).

4. O. Niwa, M. Kakuchi and T. Tamamura, Macromolecules, 29, 749 (1987).

5. R. Qian and J. Qiu, Polym. J., 19, 157 (1987).

6. K. Koga, T. Iino, S. Ueta, and M. Takayanagi, Polym. J., in press.

7. K. Koga, S. Ueta, and M. Takayanagi, Polym. J., 20, 639 (1988).

8. M. Takayanagi and T. Katayose, J. Polym. Sci., Polym. Phys. Ed., 25, 2179 (1981).

9. K. J. Wynne and G. B. Street, Macromolecules, 18, 2361 (1985).

10. G. B. Street, S. E. Linsey, A. I. Nazzal, and K. J. Wynne, Mol. Cryst. Liq. Cryst., 118, 137 (1984).

11. L. J. Buckley, D. K. Roylance, and G. E. Wnek, J. Polym. Sci., Polym. Phys. Ed., 25, 2179 (1987).

12. W. Wernet, M. Monkenbusch, and G. Wegner, Makromol. Chem., Rapid Commun., 5, 157 (1984).

13. M. Yamaura, T. Hagiwara, and K. Iwata, Synth. Met., 26, 209 (1988). 